\title{
Changes in quality of life associated with fragility fractures: Australian arm of the International Cost and Utility Related to Osteoporotic Fractures Study (AusICUROS)
}

\author{
J. Abimanyi-Ochom • J. J. Watts • F. Borgström • G. C. Nicholson • C. Shore-Lorenti • \\ A. L. Stuart • Y. Zhang • S. Iuliano • E. Seeman • R. Prince $\cdot$ L. March $・$ M. Cross \\ T. Winzenberg • L. L. Laslett • G. Duque • P. R. Ebeling • K. M. Sanders
}

Received: 17 November 2014 / Accepted: 23 February 2015 / Published online: 20 March 2015

(C) The Author(s) 2015. This article is published with open access at Springerlink.com

\begin{abstract}
Summary We investigated change in health-related quality of life due to fracture in Australian adults aged over 50 years. Fractures reduce quality of life with the loss sustained at least over 12 months. At a population level, the loss was equivalent to 65 days in full health per fracture.

Purpose We aimed to quantify the change in health-related quality of life (HRQoL) that occurred as a consequence of a fracture using the EQ-5D-3 L questionnaire.

Methods Adults aged $\geq 50$ years with a low to moderate energy fracture were recruited from eight study centres across
\end{abstract}

Electronic supplementary material The online version of this article (doi:10.1007/s00198-015-3088-z) contains supplementary material, which is available to authorized users.

\section{J. Abimanyi-Ochom $(\bowtie) \cdot J$. J. Watts}

Deakin Health Economics, Population Health Strategic Research

Centre, Deakin University, Burwood, VIC, Australia

e-mail: j.abimanyiochom@deakin.edu.au

F. Borgström

LIME/MMC, Karolinska Institutet, Solna, Sweden

G. C. Nicholson • C. Shore-Lorenti • Y. Zhang • P. R. Ebeling •

K. M. Sanders

Australian Institute of Musculoskeletal Science, Department of

Medicine, The University of Melbourne-Western Health,

Melbourne, VIC, Australia

G. C. Nicholson

Rural Clinical School, The University of Queensland,

Toowoomba, QLD, Australia

\section{A. L. Stuart · Y. Zhang}

School of Medicine, Deakin University, Geelong, VIC, Australia

S. Iuliano $\cdot$ E. Seeman

Department of Medicine, Austin Health, The University of

Melbourne, Melbourne, VIC, Australia
Australia. This prospective study included an 18-month follow-up of participants recruited within 2 weeks of a fracture (hip, wrist, humerus, vertebral and ankle). Information collected at baseline and 4,12 and 18 months included characteristics of participants such as income level, education and prior fracture status. At 12 months post-fracture, the cumulative loss of quality of life was estimated using multivariate regression analysis to identify the predictors of HRQoL loss.

Results Mean HRQoL for all participants before fracture was 0.86 , with wrist fracture having the highest pre-fracture HRQoL (0.90), while vertebral fracture had the lowest

\section{R. Prince}

Sir Charles Gairdner Hospital, Perth, WA, Australia

L. March $\cdot$ M. Cross

Institute of Bone and Joint Research, University of Sydney-Royal

North Shore Hospital, Sydney, NSW, Australia

T. Winzenberg $\cdot$ L. L. Laslett

Menzies Research Institute Tasmania, University of Tasmania,

Tasmania, TAS, Australia

G. Duque

Ageing Bone Research Program, Sydney Medical School, Nepean

Hospital, University of Sydney, Sydney, NSW, Australia

P. R. Ebeling

Department of Medicine, School of Clinical Sciences, Monash

University, Melbourne, VIC, Australia

K. M. Sanders

Institute for Health and Ageing, Australian Catholic University, Melbourne, VIC, Australia 
(0.80). HRQoL declined to 0.42 in the immediate postfracture period. Only participants with a wrist, humerus or ankle fracture returned to their pre-fracture HRQoL after 18 months. An increased loss of HRQoL over 12 months was associated with HRQoL prior to the fracture, hospitalisation, education and fracture site. The multiple regression explained $30 \%$ of the variation in the cumulative HRQoL loss at 12 months post-fracture for all fractures.

Conclusion Low to moderate energy fractures reduce HRQoL, and this loss is sustained for at least 12 months or, in the case of hip and spine fractures, at least 18 months. At a population level, this represents an average loss of 65 days in full health per fragility fracture. This significant burden reinforces the need for cost-effective fracture prevention strategies.

Keywords Ankle $\cdot$ Fracture $\cdot$ Health-related quality of life . Humeral · Prospective

\section{Introduction}

Bone fragility is expressed clinically as fractures, most often occurring following minimal or low energy impact. Fractures cause acute pain and loss of function. Recovery can be slow and rehabilitation is often incomplete [1]. Fragility fractures of the hip and vertebrae are commonly associated with high morbidity even though fractures at other sites collectively account for $60-70 \%$ of all fractures [1]. Fragility fractures are likely to be associated with an increased risk of mortality [2].

Years of life lost can be directly quantified by measuring the difference between the individual's age at death as a consequence of the fracture, and the mean age of death for their country, adjusted for sex. However, it is more difficult and less objective to quantify the pain, disturbance of physical function, decreased mobility and social interaction commonly associated with fractures, yet these make an important contribution to the morbidity and costs of fractures to both individuals and society. This burden imposed by fractures is quantifiable as a change in health-related quality of life (HRQoL), which is measured using validated questionnaires such as the EQ-5D [3]. The assessment of quality-adjusted life year (QALY) loss associated with fragility fractures allows the burden of osteoporosis to be compared with that of other diseases and can be used to inform health care policy.

The study (AusICUROS) represents the Australian 'arm' of an international health economics study on fragility fractures, the International Costs and Utilities Related to Osteoporotic Fractures (ICUROS) [4]. Using a uniform study design, the prospective study was conducted at eight centres across Australia to estimate costs and quality of life (QoL) related to fragility fractures. Direct and indirect resource data were also collected as part of the AusICUROS project, and these results are currently available as a burden of disease report for Osteoporosis Australia [5].

Our primary objective was to quantify the change in quality of life that occurred as a consequence of a fragility fracture in a cohort of Australian adults. A secondary objective was to explore factors that predicted the change in HRQoL at 12 months following a fragility fracture.

\section{Method}

Study design and population

Eligibility to the AusICUROS project specified Australian adults aged 50 years and over with an incident 'low/moderate energy' fracture. Participants were recruited between July 2009 and July 2012. Recruitment mainly occurred through emergency departments and acute hospital orthopaedic wards. Individuals with fractures at more than one anatomical site were excluded from the study. There were eight study sites across Australia representing five of the six states and two territories in Australia (Electronic Supplementary Material 1). Each site was associated with an acute hospital and an emergency department. The study was approved by the relevant human research ethics committees (HREC) in each of the eight participating study centres in Australia (lead site Barwon Health HREC Approval number 09/49).

\section{Data collection}

The prospective study design has been described elsewhere [4], but in brief, participants were enrolled within 2 weeks after the low-moderate energy fracture event and followedup for 18 months which involved data collection at five phases (phases 0 to 4: Supplementary Fig. S1). The baseline interview included phases 0 and 1 ; phase 0 represented the patient's recollection of their health state just prior to the fracture, while phase 1 represented their self-assessed health state at the time of fracture. The data/information for phases 0 and 1 was primarily collected in hospital by interview while the patient was receiving care for their fracture, and in some instances, was undertaken by telephone interview. Details of the fracture event and participant age, education (highest level attained), income category (low, middle or high) and prior fracture history were collected by self-report at the baseline interview (Table 1). Phases 2, 3 and 4 took place at 4, 12 and 18 months, respectively, after the fracture event, at which time telephone interviews were used to collect data on current HRQoL and fracture-related resource use since the last interview (Supplementary Fig. S1). HRQoL was estimated using the EuroQoL 


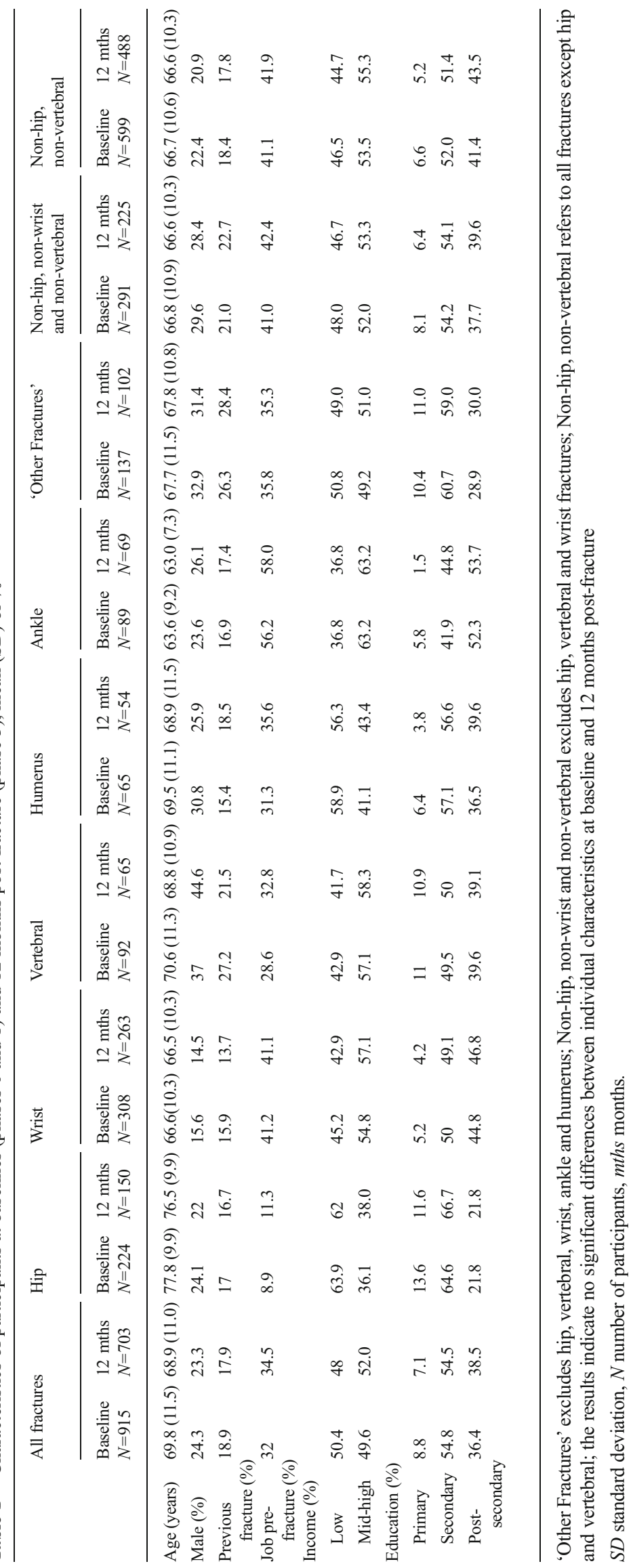


EQ-5D-3 L questionnaire, a time trade-off (TTO) questionnaire described below (Table 2).

\section{Analysis of quality of life}

Changes in HRQoL were assessed utilising the widely used and validated EQ-5D-3 L questionnaire. Generic HRQoL questionnaires such as the EQ-5D enable comparisons of quality of life across different diseases or health states using a single index. The EQ-5D-3 L has five dimensions-mobility, self-care, usual activities, pain/discomfort and anxiety/ depression - each with three levels of severity (no problem, some problem and major problem). The dimensions and levels present $3^{5}$ or 243 possible health state combinations (including full health (1) and dead (0)) [6]. Where there were missing values in any domain of the EQ-5D questionnaire, these were replaced with the sample mean to allow the utility score to be calculated.
The health state identified by the EQ-5D is quantified as a single measure of utility by weighting the health state based on population norms. The values attached to each of these health states were based on the Australian time trade-off (TTO) utility weights from general Australian population samples [7]. For comparison between international studies, UK weights are also presented (Electronic Supplementary Material Table S1). The utility that results is expressed as a fraction with 0 representing death and 1 , perfect health. Negative values are possible and represent 'worse than death'. When utility is measured at two time points, the change is then expressed as a quality-adjusted life year (QALY). If the difference in the utility score is 0.5 , then this is equivalent to a loss/gain of one half a quality-adjusted life year, which is equivalent to a loss/gain of 6 months in full health. The decrement in utility associated with fractures is the cumulative loss of utility over a given time period. For example, if a fracture causes a utility change from 1.0 to 0.6 for 1 year, the

Table 2 Mean health-related utility (EQ-5D) and percentage change from baseline to fracture, 4, 12 and 18 months, by fracture site

\begin{tabular}{|c|c|c|c|c|c|}
\hline \multirow[t]{2}{*}{ Fracture site } & \multicolumn{5}{|c|}{ Mean utility index (SD), \% change from baseline, sample size } \\
\hline & $\begin{array}{l}\text { Before fracture } \\
\text { (phase 0) }\end{array}$ & $\begin{array}{l}\text { At fracture } \\
\text { (phase 1) }\end{array}$ & $\begin{array}{l}4 \text { mths PF } \\
\text { (phase 2) }\end{array}$ & $\begin{array}{l}12 \text { mths PF } \\
\text { (phase 3) }\end{array}$ & $\begin{array}{l}18 \text { mths PF } \\
\text { (phase 4) }\end{array}$ \\
\hline All fractures & $\begin{array}{l}0.86(0.19) \\
N=915\end{array}$ & $\begin{array}{l}0.42(0.28) \\
-51.2 \% \\
N=915\end{array}$ & $\begin{array}{l}0.74(0.22) \\
-14.0 \% \\
N=795\end{array}$ & $\begin{array}{l}0.80(0.21) \\
-7.0 \% \\
N=703\end{array}$ & $\begin{array}{l}0.83(0.22) \\
-3.5 \% \\
N=543\end{array}$ \\
\hline Hip & $\begin{array}{l}0.84(0.20) \\
N=224\end{array}$ & $\begin{array}{l}0.26(0.25) \\
-69.0 \% \\
N=224\end{array}$ & $\begin{array}{l}0.69(0.22) \\
-17.9 \% \\
N=175\end{array}$ & $\begin{array}{l}0.74(0.22) \\
-11.9 \% \\
N=150\end{array}$ & $\begin{array}{l}0.73(0.25) \\
-13.1 \% \\
N=114\end{array}$ \\
\hline Wrist & $\begin{array}{l}0.90(0.17) \\
N=308\end{array}$ & $\begin{array}{l}0.58(0.22) \\
-35.6 \% \\
N=308\end{array}$ & $\begin{array}{l}0.82(0.19) \\
-8.9 \% \\
N=285\end{array}$ & $\begin{array}{l}0.88(0.18) \\
-2.2 \% \\
N=263\end{array}$ & $\begin{array}{l}0.90(0.17) 0 \% \\
N=233\end{array}$ \\
\hline Vertebral & $\begin{array}{l}0.80(0.21) \\
N=92\end{array}$ & $\begin{array}{l}0.43(0.28) \\
-46.3 \% \\
N=92\end{array}$ & $\begin{array}{l}0.68(0.27) \\
-15.0 \% \\
N=81\end{array}$ & $\begin{array}{l}0.73(0.25) \\
-8.8 \% \\
N=65\end{array}$ & $\begin{array}{l}0.71(0.28) \\
-11.3 \% \\
N=51\end{array}$ \\
\hline Humerus & $\begin{array}{l}0.82(0.17) \\
N=65\end{array}$ & $\begin{array}{l}0.34(0.26) \\
-58.5 \% \\
N=65\end{array}$ & $\begin{array}{l}0.72(0.18) \\
-12.2 \% \\
N=58\end{array}$ & $\begin{array}{l}0.78(0.16) \\
-4.9 \% \\
N=54\end{array}$ & $\begin{array}{l}0.83(0.13) 1.2 \% \\
N=34\end{array}$ \\
\hline Ankle & $\begin{array}{l}0.86(0.19) \\
N=89\end{array}$ & $\begin{array}{l}0.34(0.24) \\
-60.5 \% \\
N=89\end{array}$ & $\begin{array}{l}0.70(0.18) \\
-18.6 \% \\
N=80\end{array}$ & $\begin{array}{l}0.79(0.18) \\
-8.1 \% \\
N=69\end{array}$ & $\begin{array}{l}0.87(0.13) 1.2 \% \\
N=46\end{array}$ \\
\hline 'Other Fractures' & $\begin{array}{l}0.85(0.19) \\
N=137\end{array}$ & $\begin{array}{l}0.37(0.28) \\
-56.5 \% \\
N=137\end{array}$ & $\begin{array}{l}0.71(0.25) \\
-16.5 \% \\
N=116\end{array}$ & $\begin{array}{l}0.75(0.24) \\
-11.8 \% \\
N=102\end{array}$ & $\begin{array}{l}0.82(0.23) \\
-3.5 \% \\
N=65\end{array}$ \\
\hline Non-hip, non-wrist and non-vertebral & $\begin{array}{l}0.85(0.18) \\
N=291\end{array}$ & $\begin{array}{l}0.36(0.27) \\
-57.6 \% \\
N=291\end{array}$ & $\begin{array}{l}0.71(0.21) \\
-16.5 \% \\
N=253\end{array}$ & $\begin{array}{l}0.77(0.21) \\
-9.4 \% \\
N=225\end{array}$ & $\begin{array}{l}0.84(0.18) \\
-1.2 \% \\
N=145\end{array}$ \\
\hline Non-hip, non-vertebral & $\begin{array}{l}0.86(0.21) \\
N=599\end{array}$ & $\begin{array}{l}0.38(0.35) \\
-55.8 \% \\
N=599\end{array}$ & $\begin{array}{l}0.75(0.25) \\
-12.8 \% \\
N=537\end{array}$ & $\begin{array}{l}0.81(0.23) \\
-5.8 \% \\
N=488\end{array}$ & $\begin{array}{l}0.87(0.20) \\
1.2 \% \\
N=378\end{array}$ \\
\hline
\end{tabular}

Unit of measurement is utility score where $1=$ perfect health and $0=$ death. 'Other Fractures' excludes hip, vertebral, wrist, ankle and humerus; Non-hip, non-wrist and non-vertebral excludes hip, vertebral and wrist fractures; Non-hip, non-vertebral refers to all fractures except hip and vertebral 
QALY loss is 0.4; alternatively, if the fracture causes a utility loss of 0.4 for 6 months, the QALY loss is 0.2 .

Fracture site

Participants were enrolled into the study with a low-moderate energy fracture. The most common of these were hip, wrist, vertebral, humerus and ankle; however, fractures at other sites were also included. Vertebral fractures were identified by radiologist's report and were excluded if the decrease in vertebral height was less than $20 \%$. This analysis has included HRQoL data for the individual fracture sites as well as for combinations of fractures: 'Other Fractures' (excludes hip, vertebral, wrist, ankle and humerus); 'Non-hip, non-wrist and non-vertebral' (excludes hip, vertebral and wrist fractures); and 'Non-hip, non-vertebral' (includes fracture sites other than hip and vertebral).

\section{Statistical analysis}

Mean EQ-5D indices were reported for hip, vertebral, wrist, humeral, ankle and 'other' fragility fractures at each time point from phases 0 to 4 , as well as the change in HRQoL over 12 months. Calculation of the cumulative loss in HRQoL from phase 0 (the individual's recollection of their quality of life pre-fracture) to phase 3 (12 months after fracture) was calculated according to the following formula:

QALY loss $=\mathrm{QoL}_{0}-\left[\left(\left(\mathrm{QoL}_{2}-\mathrm{QoL}_{1}\right) / 2+\left(\mathrm{QoL}_{2}-\mathrm{QoL}_{1}\right)\right) * 4 / 12+\left(\left(\mathrm{QoL}_{3}-\mathrm{QoL}_{2}\right) / 2+\left(\mathrm{QoL}_{3}-\mathrm{QoL}_{2}\right)\right) * 8 / 12\right]$

Where $\mathrm{QoL}_{0}=$ pre-fracture HRQoL, $\mathrm{QoL}_{1}=\mathrm{HRQoL}$ at fracture, $\mathrm{QoL}_{2}=\mathrm{HRQoL}$ at 4 months and $\mathrm{QoL}_{3}=\mathrm{HRQoL}$ at 12 months, and the assumption is that if the fracture had not occurred, pre-fracture HRQoL would have been unchanged over 12 months.

The change in utility value was calculated as a mean QALY lost and as a percentage change in QALYs over 12 months.

Multivariate regression analyses by fracture site for all fractures and the individual fracture sites (hip, wrist, vertebral, humerus and ankle) were undertaken to identify determinants of QALY loss [8]. The variables included in the models were HRQoL at baseline, age (in years), gender, whether hospitalisation occurred in connection with the fracture, presence or absence of a fracture in the previous 5 years, income (low or mid-high income level) and education (primary, secondary and post-secondary) and, in the model for all fractures, fracture site (hip, wrist, vertebral, humerus, ankle and other). Where complete data or observations were missing, no assumptions were made.

\section{Results}

Population characteristics

A total of 915 participants completed phases 0 and 1 at baseline and 703 participants completed phase 3 at 12 months (Table 1). Participant numbers by fracture site with numbers lost to follow-up and total assessed at each time point are presented in Fig. 1. At 12 months post-fracture, loss to

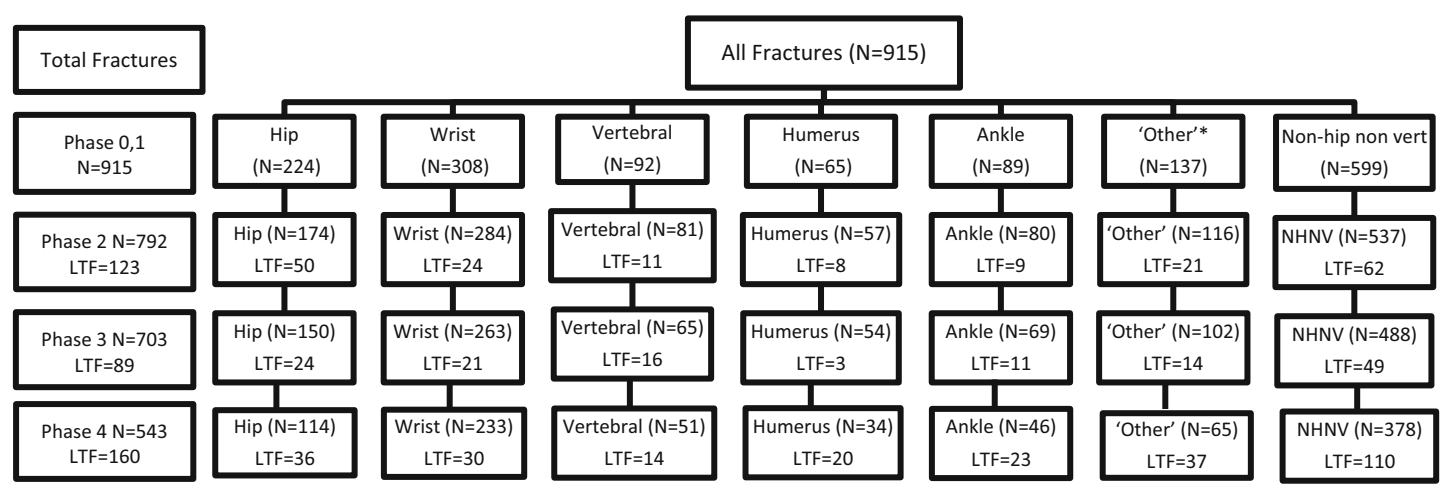

*LTF refers to lost to follow-up, NHNV=non-hip, non-vertebral; 'Other' fracture site (N) at phase 0,1: tibia/fibula(N=32), $\operatorname{rib}(N=24)$, other femoral( $N=17)$, forearm(not wrist) $(N=16)$, pelvic $(N=10)$, foot $(N=10)$, patella $(N=8)$, clavicle $(N=8)$ and other(N=12); * refers to Other; Group 1..

Fig. 1 Number of participants and lost to follow-up by fracture type and phase 
follow-up was $23 \%$ (212/915). There were missing data for $8.7 \%(61 / 703)$ of the participants at 12 months. There were three participants at 12 months who had missing values in one domain of the EQ-5D questionnaire; these were replaced with the sample mean to allow utility scores to be calculated. Mean age of participants at baseline was 69.8 years (SD 11.5) and at 12 months 69.9 years (SD 11.0). Hip fracture participants were older (mean age 78 years; SD 9.9) and ankle fracture participants were younger (mean age 64 years; SD 9.2). Male participants having fractures at the wrist, vertebrae or 'other fracture site' were younger than females. Almost $76 \%$ of participants were women. Vertebral fractures had the highest proportion of men (37\%) and hip fractures the lowest (16\%) (Table 1). There were no significant differences between the groups measured at baseline and at 12 months.

\section{Quality of life}

The mean pre-fracture HRQoL utility index (estimated by recall) for all fractures was 0.86 (SD 0.19) (Table 3). This declined to a mean of 0.42 (SD 0.28) in the immediate postfracture period corresponding to a $51 \%$ decline. At 4,12 and 18 months post-fracture, HRQoL improved to 0.74 (SD 0.22), 0.80 (SD 0.21) and 0.83 (SD 0.22), respectively, although it did not fully return to the pre-fracture baseline level (Table 3).

The pre-fracture HRQoL was highest for wrist fracture participants $(0.90$; SD 0.17$)$ who tended to be younger and was lowest for vertebral fracture participants $(0.80 ;$ SD 0.21$)$. During the immediate fracture period (phase 1), hip fracture participants' HRQoL declined by $69 \%$ although HRQoL substantially declined for all fractures: ankle $(61 \%)$, humerus $(59 \%)$, other $(57 \%)$, vertebral $(46 \%)$ and wrist fracture $(36 \%)$. Health-related quality of life improved with time from the fracture event (Fig. 2). However, at 12 months after fracture, no fracture site had attained the pre-fracture HRQoL, and by 18 months, HRQoL for hip and vertebral fracture participants remained 13 and $11 \%$ lower than pre-fracture estimates, respectively. By 18 months, HRQoL for the other fracture sites had attained pre-fracture levels.

At 4 months post-fracture, HRQoL was rated similarly for all fracture sites except the wrist which was highest at 0.82 (SD 0.19) (Table 3). To facilitate direct comparisons with international data, utilities using UK weights are presented in Appendix Table S1. In general, QALY estimates using UK weights were lower than the Australian weighted QALYs.

Changes in quality-adjusted life years

The mean cumulative loss in quality-adjusted life years (QALYs) for all fractures from pre-fracture to 12 months was 0.157 , which represented an $18 \%$ loss in QALYs from baseline (Table 4). Hip and ankle fractures had the greatest loss of QALYs over 12 months (26 and $24 \%$, respectively) while wrist fractures had the smallest decline of $11 \%$.

Predictors of loss of quality-adjusted life years at 12 months (regression analyses)

The full model in Table 4 shows the predictors of QALY loss for all fractures adjusted for age, gender, fracture site, prefracture HRQoL, hospitalisation, previous fracture, income, employment and education, as well as a separate model predictive of QALY loss for each fracture site. The baseline HRQoL utility index score was a significant predictor of loss of QALYs from baseline to 12 months post-fracture (Table 4 and Supplementary Table S2) for all fractures. The model predicted that those with a higher baseline HRQoL experience a substantially greater loss in QALYs at 12 months.

Compared with a wrist fracture, the mean loss of QALYs was $13 \%$ higher for a hip fracture and was also $11 \%$ higher

Table 3 Cumulative loss of quality-adjusted life years (QALYs) by fracture type at 12 months post-fracture

\begin{tabular}{llll}
\hline Fracture site & No. of participants & Mean QALY lost & QALY lost (\%) \\
\hline All fractures & $N=703$ & $0.156(0.180)$ & 18 \\
Hip & $N=150$ & $0.216(0.196)$ & 26 \\
Wrist & $N=263$ & $0.099(0.144)$ & 11 \\
Vertebral & $N=65$ & $0.162(0.215)$ & 20 \\
Humerus & $N=54$ & $0.142(0.186)$ & 17 \\
Ankle & $N=69$ & $0.208(0.165)$ & 24 \\
'Other Fractures' & $N=102$ & $0.182(0.178)$ & 21 \\
Non-hip, non-wrist and non-vertebral & $N=224$ & $0.181(0.177)$ & 21 \\
Non-hip, non-vertebral & $N=486$ & $0.137(0.165)$ & 16
\end{tabular}

Expressed as mean utility value with standard deviation in parentheses; 'Other Fractures' excludes hip, vertebral, wrist, ankle and humerus; Non-hip, non-wrist and non-vertebral excludes hip, vertebral and wrist fractures; Non-hip, non-vertebral refers to all fractures except hip and vertebral 
Fig. 2 Mean utility index (EQ5D) by fracture type; phases 0 to 4 (with $95 \%$ confidence interval)

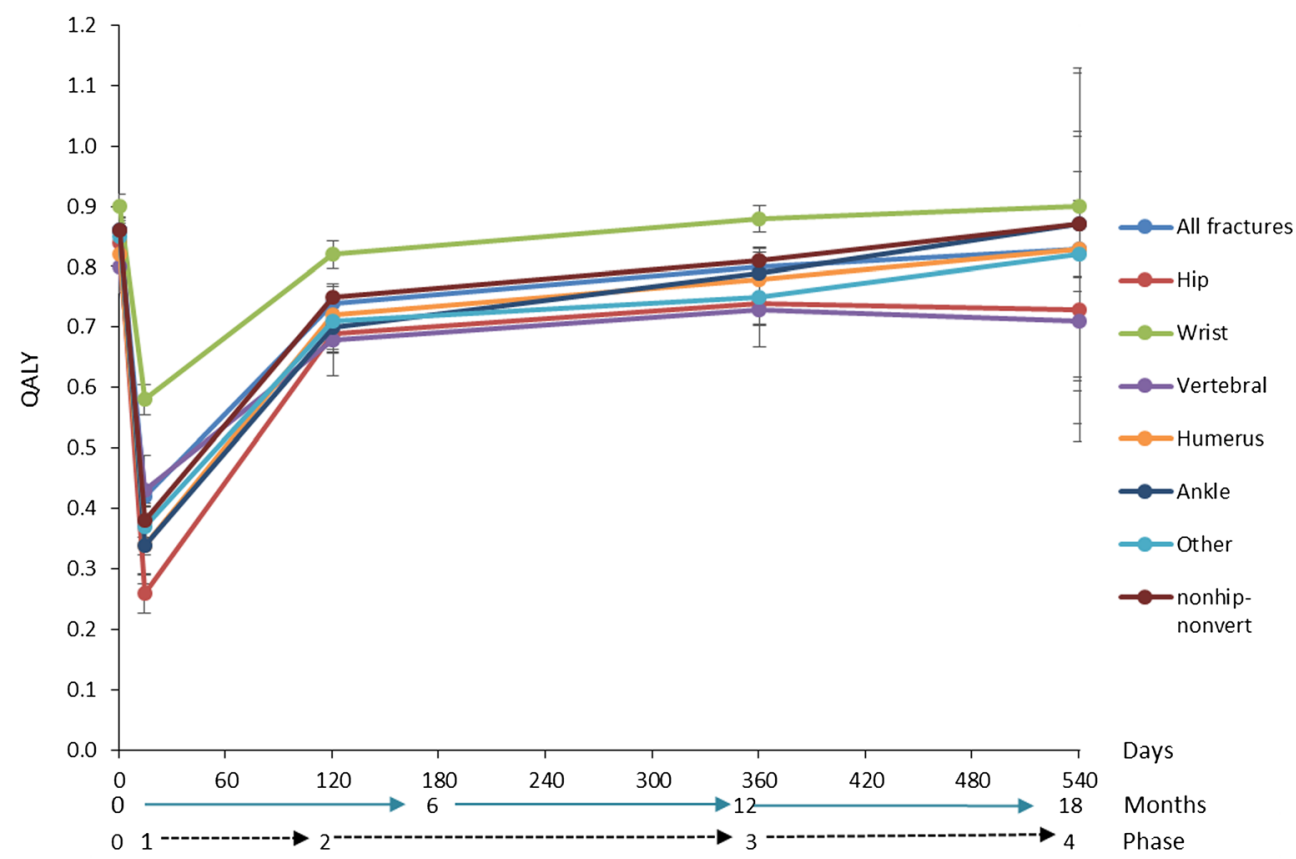

than ankle or vertebral fracture (Table 4 'All Fractures'). When adjusted for fracture site, hospitalisation as a result of a fracture was associated with a $3 \%$ increased loss of QALYs over 12 months. However, this was not significant for any single fracture site.

In the full model for all fractures, individuals with a postsecondary education were more likely to experience a smaller loss in QALYs compared to individuals with a secondary education. For individuals with a hip fracture, post-secondary education was associated with an $11 \%$ lower loss of QALYs, and for primary education, the QALY loss was $7 \%$ higher (both significant) compared with secondary education (Table 4). However, education was not a significant predictor for QALY loss for other fracture sites.

For hip fractures, not other fractures, being employed prefracture was a predictor of a $13 \%$ increase in the loss of QALYs over 12 months. Mid to high income was associated with a decrease in the loss of QALYs for humeral and ankle fractures (14 and $9 \%$, respectively) compared with having a low income, whilst mid to high income was predictive of an increase in the loss of QALYs for vertebral fractures (13\%). Having a fracture in the last 5 years, gender and age were not significant predictors for a loss of QALYs for all fractures, or for any individual fracture.

The adjusted $R^{2}$ for the regression equation demonstrated that over $30 \%$ of the variation in QALY loss at 12 months was explained by the full model predictors (All fractures). Predictor variables explained almost $25 \%$ of the variation for wrist fractures, to over $56 \%$ for humeral fractures in the fracturesite-specific regression (Table 4).

\section{Discussion}

This is the first study to quantify change in HRQoL following an acute low-moderate energy fracture in Australian older adults and the associated loss in quality-adjusted life years. We estimated a mean loss of $18 \%$ in QALYs across all fractures over 12 months, which is equivalent to an average loss of 65 days in full health for each fragility fracture. This represents a substantial health impact. Further analysis by fracture site found that the pattern associated with HRQoL assessed within 2 weeks of the fracture, then at 4,12 and 18 months was similar for all fracture sites; however, the magnitude of the change differed according to fracture site. Of importance, these data show that the HRQoL for non-hip, non-vertebral fractures does not reach pre-fracture levels until 12 to 18 months post-fracture, while the post-fracture HRQoL decrement associated with hip and vertebral fractures is sustained and remains 13 and $11 \%$ lower respectively, at 18 months.

The study included a follow-up period of 18 months and a large number of participants from several study centres across Australia. The cohort reflects the typical profile of fracture incidence statistics associated with osteoporosis, with three quarters of participants being female and a mean age around 70 years [9]. The cohort was unique in collecting HRQoL data from all fracture sites including separate estimates for hip, vertebral, wrist, ankle and humeral fractures in addition to other fractures grouped. Previous post-fracture HRQoL work has been largely confined to single fracture sites including hip $[1,4,10-15]$, vertebral $[1,4,10,11,14,16]$, distal forearm $[10,16,17]$, proximal humerus $[15,16]$, pelvic and rib 


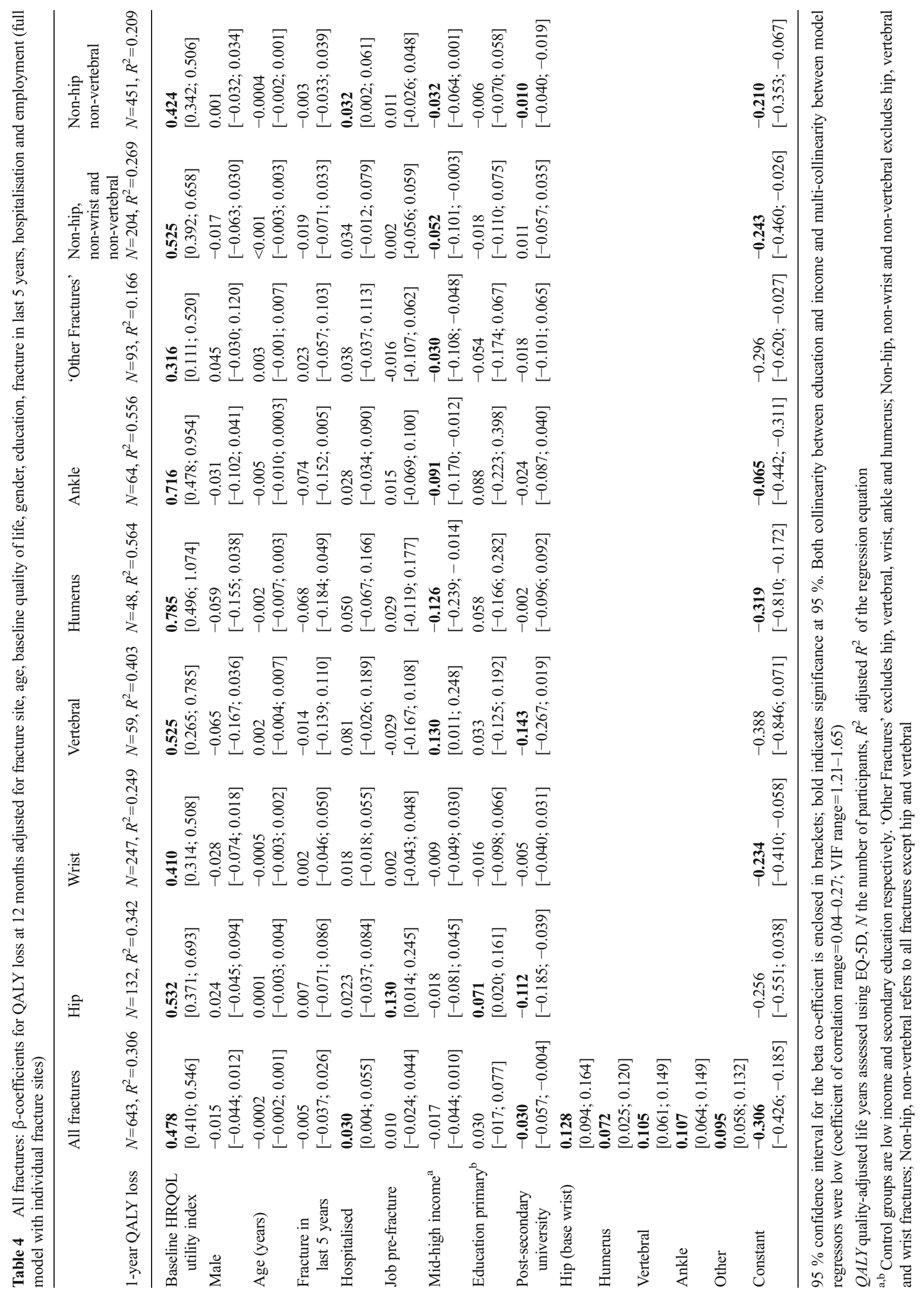


fractures [10]. Prospective cohort studies measuring HRQoL over time after an acute event are not common. Longitudinal studies that have assessed HRQoL following an acute event include stroke [18], acute myocardial infarction [19] and total joint replacement [20]. However, the emphasis is more on understanding the predictors of HRQoL rather than quantifying the amount.

In the immediate acute fracture period, quality of life declined by a mean of $51 \%$, ranging from almost $70 \%$ posthip fracture to $36 \%$ post-wrist fracture. Notably, at 4 months post-fracture, the decline in HRQoL for ankle fracture was similar to that for hip fracture, suggesting that factors such as mobility that impact on HRQoL are equally relevant in both hip and ankle fractures at 4 months. At 12 months post-fracture, HRQoL for ankle fractures was $8 \%$ lower than the pre-fracture level. The mean decline of all non-hip, non-vertebral fractures at 12 months post-fracture was $6 \%$ lower than pre-fracture level with attainment of the pre-fracture level by 18 months.

Interim analysis of international hip, vertebral and wrist data from the parent ICUROS study also found no significant difference in loss of HRQoL at 4 months between participants with and without prior fracture [4] and reports that the strongest and most consistent predictor of HRQoL at 4 months post-fracture was baseline HRQoL. Our Australian data confirm this and demonstrate that those with a higher pre-fracture HRQoL experienced a greater decline in HRQoL over the 18 months following fracture.

The decrement in HRQoL did not differ by sex while age $(70+$ years $)$ conferred only a minor extra decline in HRQoL compared with participants' aged 50 to 69 years. A previous fracture in the past 5 years was not associated with QALY loss at 12 months. Hospitalisation as a consequence of the acute fracture resulted in an additional $5 \%$ loss of QALYs for all fractures, and $3 \%$ loss for non-hip, non-vertebral fractures. This is probably due to hospitalisation being a potential marker of either fracture severity, or poorer health. The effects of education and income were mixed with respect to direction and fracture type.

At 1 year post-fracture, there was a $22 \%$ loss in QALYs among our Australian cohort of 150 hip fracture participants. Similarly, the Belgian Hip Fracture Study Group, using the SF-36 tool rather than the EQ-5D, reported a $24 \%$ functional decline [21]. QALY loss in the first 12 months after hip fracture was estimated to be 0.47 mainly due to hospital and nursing home stay [1]. In contrast for wrist fracture, our Australian estimate of 0.10 QALY loss at 12 months is higher than the 0.05 reported by the National Osteoporosis Foundation [22].

There are limited published data on the quality of life decline associated with humeral fractures [23] despite it being the fourth most common site for fracture among Australians aged 50 years and over $(0.4 \%$ per year (p.a). for women and $0.1 \%$ p.a. for men [9]). In our Australian cohort, the decline in HRQoL was greater than for wrist fracture (QALY: 18 vs $11 \%$ at 12 months) while Hallberg et al. using the SF-36 tool reported that humeral fractures had a similar pattern to that of wrist fracture with less decline compared with vertebral fracture [23]. These Australian data show that the decline in quality of life for humeral fractures was greater in the immediate fracture period than for vertebral fractures (59 vs $47 \%$, respectively) although, in contrast to vertebral fracture, HRQoL returned to pre-fracture levels by 18 months.

While participants with ankle fracture were on average 3 years younger than those with wrist fracture (63.6 and 66.6 years, respectively), the cumulative loss of QALYs at 12 months was double that of wrist fractures ( 24 vs $11 \%$, respectively). The decline in quality of life over 12 months was similar to that following vertebral fracture. However, at 18 months post-fracture, HRQoL had returned to the pre-fracture level.

A potential limitation of this study is that participants were asked for their pre-fracture HRQoL after their fracture. The participant may therefore perceive their pre-fracture status as better than it was, potentially overestimating the loss in HRQoL. However, Marsh et al. have reported that older patients can accurately recall their preoperative health status 6 weeks following hip arthroplasty [24]. Another limitation is the relatively low number of vertebral fractures compared with other fracture sites $(92 / 915 ; 10 \%)$. In Australia, vertebral fracture patients not involved in a high trauma event do not routinely present at a hospital emergency department. They are more likely to present to a general practitioner, but this may not be within 2 weeks of their fracture, as required for this study. To improve recruitment of people with a vertebral fracture, financial bonuses were offered to site coordinators. As the majority of fracture participants were recruited through attendance at an emergency department, the vertebral fracture cohort is likely to be those who present with a sudden and acute onset of pain. These patients may therefore represent those who experience a large and immediate decline in HRQoL and may not be representative of the general vertebral fragility fracture population. A third limitation is that deaths during the follow-up period were excluded in further analysis, therefore suggesting that our QALY estimates may be conservative.

Quality of life is reported using a generic questionnaire (EQ-5D) which can be expressed as a single index that enables comparison of HRQoL across diseases or populations, for example, in priority setting. The assessment of QALY loss associated with fragility fracture allows the burden of osteoporosis to be compared with that of other diseases and can be used to drive change in health care policy. The reported estimates of HRQoL can also be used in cost-effectiveness analyses of different treatment scenarios, as well as the potential value of directing community health resources towards primary and secondary fracture prevention.

In summary and conclusion, fractures reduce quality of life. These novel data highlight the neglected and significant decline in HRQoL associated with fractures at sites other than the hip, 
vertebrae and wrist. They also show that the HRQoL for non-hip, non-vertebral fractures does not reach pre-fracture levels until 12 to 18 months post-fracture. On the other hand, the HRQoL decrement associated with hip and vertebral fractures is sustained at 18 months post-fracture. Previous estimates of the full impact on HRQoL associated with fragility fractures are likely to represent an underestimate as the observational period does not generally extend past 12 months and are not inclusive of all fracture sites.

Acknowledgments We are grateful to the Quality of Life and Epidemiology Working Group of the Committee of Scientific Advisors for the International Osteoporosis Foundation under whose supervision this study was undertaken. The ICUROS was supported in Australia by Project Grant No. 628422 from the National Health and Medical Research Council with subsidiary funding support from Merck Australia Pty Ltd. Quality of Life and Epidemiology Working Group: Jonathan Adachi, Frederik Borgström, Patricia Clark, Cyrus Cooper (co-chair), Manuel Diaz Curiel, Hans Peter Dimai, Mickaël Hiligsmann, John Kanis (cochair), Edith Lau, Paul Lips, Mickael Lewiecki, Roman Lorenc, Eugene McCloskey, Sergio Ortolani, Alexandra Papaioannou, Stuart Silverman and Pawel Szulc.

\section{Conflicts of interest None}

Open Access This article is distributed under the terms of the Creative Commons Attribution Noncommercial License which permits any noncommercial use, distribution, and reproduction in any medium, provided the original author(s) and the source are credited.

\section{References}

1. Lips P, van Schoor N (2005) Quality of life in patients with osteoporosis. Osteoporos Int 16(5):447-455. doi:10.1007/s00198-004-1762-7

2. Center JR, Nguyen TV, Schneider D, Sambrook PN, Eisman JA (1999) Mortality after all major types of osteoporotic fracture in men and women: an observational study. Lancet 353(9156):878882. doi:10.1016/S0140-6736(98)09075-8

3. The EuroQol Group (1990) EuroQol - a new facility for the measurement of health-related quality of life. Health Policy 16(3):199-208. doi:10.1016/0168-8510(90)90421-9

4. Borgström F, Lekander I, Ivergård M, Ström O, Svedbom A, Alekna V, Bianchi ML, Clark P, Curiel MD, Dimai HP, Jürisson M, Kallikorm R, Lesnyak O, McCloskey E, Nassonov E, Sanders KM, Silverman S, Tamulaitiene M, Thomas T, Tosteson ANA, Jönsson B, Kanis JA (2013) The International Costs and Utilities Related to Osteoporotic Fractures Study (ICUROS) - quality of life during the first 4 months after fracture. Osteoporos Int 24(3):811-823. doi:10.1007/s00198-012-2240-2

5. Watts J, Abimanyi-Ochom J, Sanders K (2013) Osteoporosis costing all Australians A new burden of disease analysis - 2012 to 2022. Osteoporosis Australia, Melbourne

6. Brooks R (1996) EuroQol: the current state of play. Health Policy 37(1):53-72. doi:10.1016/0168-8510(96)00822-6

7. Viney R, Norman R, King MT, Cronin P, Street DJ, Knox S, Ratcliffe J (2011) Time Trade-Off Derived EQ-5D Weights for Australia. Value Health 14(6):928-936. doi:10.1016/j.jval.2011.04.009

8. Borgström F, Ivergard M (2011) Statistical Analysis Plan: International Costs and Utilities Related to Osteoporotic Fractures Study (ICUROS). International Osteoporosis Foundation, Sweden
9. Sanders KM, Seeman E, Ugoni AM, Pasco JA, Martin TJ, Skoric B, Nicholson GC, Kotowicz MA (1999) Age- and gender-specific rate of fractures in Australia: a population-based study. Osteoporos Int 10(3):240-247

10. Adachi JD, Ioannidis G, Berger C, Joseph L, Papaioannou A, Pickard L, Papadimitropoulos EA, Hopman W, Poliquin S, Prior JC, Hanley DA, Olszynski WP, Anastassiades T, Brown JP, Murray T, Jackson SA, Tenenhouse A (2001) The influence of osteoporotic fractures on health-related quality of life in community-dwelling men and women across Canada. Osteoporos Int 12(11):903-908. doi:10.1007/ s001980170017

11. Cranney A, Coyle D, Pham BA, Tetroe J, Wells G, Jolly E, Tugwell P (2001) The psychometric properties of patient preferences in osteoporosis. J Rheumatol 28(1):132-137

12. Salkeld G, Ameratunga SN, Cameron ID, Cumming RG, Easter S, Seymour J, Kurrle SE, Quine S, Brown PM (2000) Quality of life related to fear of falling and hip fracture in older women: a time trade off study Commentary: Older people's perspectives on life after hip fractures. BMJ 320(7231):341-346. doi:10.1136/bmj.320.7231.341

13. Tidermark J, Zethraeus N, Svensson O, Törnkvist H, Ponzer S (2002) Femoral neck fractures in the elderly: functional outcome and quality of life according to EuroQol. Qual Life Res 11(5):473-481. doi:10. 1023/a:1015632114068

14. Tosteson ANA, Gabriel SE, Grove MR, Moncur MM, Kneeland TS, Melton Iii LJ (2001) Impact of hip and vertebral fractures on qualityadjusted life years. Osteoporos Int 12(12):1042-1049. doi:10.1007/ s001980170015

15. Zethraeus N, Borgström F, Johnell O, Kanis J, Jönsson B (2002) Costs and quality of life associated with osteoporosis related fractures-results from a Swedish Survey. Stockholm School of Economics. http://hdl. handle.net/10419/56287. Accessed December 2013

16. Hallberg I, Rosenqvist AM, Kartous L, Löfman O, Wahlström O, Toss G (2004) Health-related quality of life after osteoporotic fractures. Osteoporos Int 15(10):834-841. doi:10.1007/s00198-004-1622-5

17. Borgström F, Zethraeus N, Johnell O, Lidgren L, Ponzer S, Svensson O, Abdon P, Ornstein E, Lunsjö K, Thorngren K, Sernbo I, Rehnberg C, Jönsson B (2006) Costs and quality of life associated with osteoporosis-related fractures in Sweden. Osteoporos Int 17(5): 637-650. doi:10.1007/s00198-005-0015-8

18. Suenkeler IH, Nowak M, Misselwitz B, Kugler C, Schreiber W, Oertel WH, Back T (2002) Timecourse of health-related quality of life as determined 3, 6 and 12 months after stroke. J Neurol 249(9): 1160-1167. doi:10.1007/s00415-002-0792-3

19. Rančić N, Petrović B, Apostolović S, Kocić B, Ilić M (2013) Healthrelated quality of life in patients after the acute myocardial infarction. Cent Eur J Med 8(2):266-272. doi:10.2478/s11536-012-0118-5

20. Gonzalez Saenz de Tejada M, Escobar A, Bilbao A, Herrera-Espiñeira C, García-Perez L, Aizpuru F, Sarasqueta C (2014) A prospective study of the association of patient expectations with changes in health-related quality of life outcomes, following total joint replacement. BMC Musculoskelet Disord 15(1):1-10. doi:10.1186/1471-2474-15-248

21. Boonen S, Autier P, Barette M, Vanderschueren D, Lips P, Haentjens P (2004) Functional outcome and quality of life following hip fracture in elderly women: a prospective controlled study. Osteoporos Int 15(2):87-94. doi:10.1007/s00198-003-1515-Z

22. National Osteoporosis Foundation (1998) Osteoporosis: review of the evidence for prevention, diagnosis and treatment and cost-effective analysis. Osteoporos Int 8(4):S83-S85. doi:10.1007/PL00022723

23. Access Economics (2001) The burden of brittle bones: costing osteoporosis in Australia. Access economics Pty limited prepared for osteoporosis Australia. Canberra, ACT

24. Rizzoli R, Boonen S, Brandi ML, Burlet N, Delmas P, Reginster JY (2008) The role of calcium and vitamin D in the management of osteoporosis. Bone 42(2):246-249. doi:10.1016/j.bone.2007.10.005 